\title{
Body mass and latitude as global predictors of vertebrate populations exposure to multiple threats
}

3 Running title: Global predictors of multiple threats

4 Pol Capdevila*1, Nicola Noviello, Louise McRae $^{2}$, Robin Freeman ${ }^{2}$, Christopher 5 Clements ${ }^{1}$

$6{ }^{1}$ School of Biological Sciences, University of Bristol, Bristol Life Sciences Building, 724 Tyndall Avenue, Bristol, BS8 1TQ, UK.

$8{ }^{2}$ Institute of Zoology, Zoological Society of London, Outer Circle, London NW1 4RY, 9 UK.

10 *Corresponding authors: pcapdevila.pc@gmail.com

11 Word count: Abstract (183), Main text (3616), References (66), Figures (5)

13 Author contributions: C.C., L.M. and R.F. conceptualised the project. R.F. and L.M

14 curate and maintain the Living Planet Database. N.N. collated body mass data. P.C.

15 and N.N. performed analyses and produced the manuscript. All co-authors 16 contributed substantially to revisions.

17 Data and materials availability: The Living Planet Database (excluding confidential 18 records) is available at: www.livingplanetindex.org/data_portal. The code and data 19 used in this study will be available at Zenodo upon acceptance and is available for 20 reviewers in https://github.com/PolCap/LPD Threats.

21 Funding: L.M. is funded by WWF UK and WWF Netherlands, C.C. is supported by 22 grant RPG2019-368. 


\section{Abstract}

24 The interactive effects of multiple threats are one of the main causes of biodiversity

25 loss, yet our understanding of what predisposes species to be impacted by multiple

26 threats remains limited. Here we analyse a global dataset of over 7000 marine,

27 freshwater, and terrestrial vertebrate populations, alongside trait, threat and

28 geographical data, to identify the factors influencing the number of threats a species

29 is subjected to at the population level. Out of a suite of predictors tested, we find that

30 body mass and latitude both are broadly available for vertebrate species, and

31 influence the number of threats a population is subjected to. Larger bodied species

32 and those nearer the equator are typically affected by a higher number of threats.

33 However, whilst this pattern broadly holds across ecosystems for most taxa,

34 amphibians and reptiles show opposing trends. We suggest that latitude and body

35 mass should be considered as key predictors to identify which vertebrate populations

36 are likely to be impacted by multiple threats. These general predictors can help to

37 better understand the impacts of the Anthropocene on global vertebrate biodiversity

38 and design effective conservation policies.

39 Keywords: Conservation, extinction, life history, living planet database, multiple 40 stressors, population dynamics, traits. 


\section{Introduction}

43 The Anthropocene is characterised by the strong influence of human activities on the

44 structure and functioning of Earth's natural systems (Steffen et al., 2011; Dirzo et al.,

45 2014). Threats like climate change, habitat loss, exploitation, pollution, or invasive

46 species, directly or indirectly caused by human activities, are reshaping the

47 biosphere at an unprecedented rate and scale (Scholes et al., 2018; Díaz et al.,

48 2019; IPCC, 2021). Although the individual effects of these threats can have strong

49 impacts (Kroeker et al., 2010; Newbold et al., 2015; Hughes et al., 2017), about 80\%

50 of species are exposed to more than one threat simultaneously (IUCN 2021). The

51 pervasiveness of multiple threats is of particular concern because of the

52 unpredictability of their interactive effects (Darling \& Côté, 2008; Côté et al., 2016).

53 Yet, our understanding of the factors driving exposure to multiple threats remains

54 limited (Maxwell et al., 2016; Hodgson et al., 2017).

Whether a population is exposed to a threat is a result of the combined effects

56 of environmental factors, species life histories, and human activity (Purvis et al.,

57 2000; Cardillo et al., 2005). Life history traits such as body mass, trophic level, or

58 habitat specificity have been linked to the vulnerability of species (Fisher \& Owens,

59 2004; Di Marco et al., 2015; Pacifici et al., 2017). For instance, species with large

60 body mass are disproportionately targeted for exploitation (Pauly et al., 1998;

61 Duncan et al., 2002), making them more vulnerable to further threats. Likewise,

62 predators usually require large home ranges and also depend on the abundance of

63 their prey species, making them vulnerable to habitat loss, as well as being a

64 common target for hunting (Cardillo et al., 2005; Wolf \& Ripple, 2016). Moreover,

65 species with low habitat specificity have the potential to be more prone to be 
66 exposed to multiple threats, given their wider range of distribution (Malcolm et al.,

67 2006; Ehrlén \& Morris, 2015; Batt et al., 2017). While the influence of all these traits

68 on the vulnerability to species extinction has been largely explored (Purvis et al.,

69 2000; Fisher \& Owens, 2004; Cardillo et al., 2005), how these contribute to the

70 predisposition of species to being exposed to multiple threats remains unknown.

The exposure of species to threats can also depend on environmental factors.

72 For instance, the prevalence and impact of anthropogenic threats differs in marine, 73 terrestrial and freshwater systems (Díaz et al., 2019). While in freshwater and

74 terrestrial ecosystems habitat loss is the most prevalent threat (Newbold et al., 2015;

75 Birk et al., 2020), exploitation represents the most pressing threat for marine species

76 (Halpern et al., 2015). On top of that, local and global threats show distinct spatial

77 clustering worldwide (Bowler et al., 2020; Harfoot et al., 2021). Many local threats

78 are directly linked to human populations (e.g., habitat loss, hunting, etc.), so their

79 presence is likely to change in line with human population density across different

80 latitudes (Santini et al., 2017). Global threats (e.g. climate change) are also non-

81 uniformly distributed, particularly across latitude (Harfoot et al., 2021; IPCC, 2021),

82 making it challenging to predict them using simple proxies (Sunday et al., 2012).

83 Understanding the role life history traits and the environmental factors

84 influencing the predisposition of vertebrate populations to be exposed to multiple 85 threats is therefore the first step to manage their effects (Maxwell et al., 2016). Here, 86 we study multiple threats by identifying factors that best predict the number of threats 87 a population is affected by. To do this, we use population-level threat data from the 88 Living Planet Database (Loh et al., 2005), containing spatially explicit data for 7826 89 populations of 2667 vertebrate species, across the seven continents and all major 
90 ecosystems. To test the influence of life history on the predisposition of species to be

91 exposed to multiple threats, we supplemented the threat data with traits which are

92 broadly available and comparable across different taxa: body mass, trophic level,

93 and habitat specificity. To test the influence of environmental factors, we also

94 supplemented the data with human population density, latitude, and system

95 (freshwater, marine or terrestrial) as proxies. We then used multilevel Bayesian

96 models to determine which factors have the strongest influence on the predisposition

97 of populations to be exposed to multiple threats.

$98 \quad$ Materials and Methods

99 Threats data

100 To determine the number of threats vertebrate populations are exposed to, we used

101 the Living Planet Database (LPD hereafter). The LPD

102 (http://livingplanetindex.org/data_portal) contains information on over 25,000

103 vertebrate populations around the world, comprising all vertebrate classes across

104 marine, freshwater, and terrestrial systems and providing population-specific

105 information such as spatial location, abundance, and threat exposure. Data are

106 collected from scientific literature, online databases, and grey literature published

107 since 1970, with at least two years of abundance; detailed inclusion criteria for the

108 LPD can be found in Collen et al., (2009). If the data source was a report of paper,

109 the entire article would be screened and the information was usually extracted from

110 the discussion. For population data shared directly form a data provider, threat

111 information was recorded in the database template form that was provided. A

112 population did not have to be in decline for a threat to be recorded. 
113 Of the 25,054 population time series making up the LPD (including

114 confidential records), 7826 contained data relating to population threat exposure.

115 Based on information from the data source, for each publication we first identified

116 whether the population was threatened, not threatened or whether its threat status

117 was unknown. In this study, we only considered those populations for which threat

118 status information was available. Threats were identified as direct or indirect human

119 activities or processes that impacted the populations for at least $50 \%$ of the surveyed

120 years, according to the original source of the time series. If the population was

121 threatened, the number of threats at which the population was exposed was

122 recorded, from one to three. The information within the data sources was sometimes

123 quantitative, e.g. stating number of individuals hunted annually, but most often it was

124 reported in a qualitative way, e.g. a describing a general pattern of hunting that

125 impacts the populations. For this reason, and because the impact of the threat was

126 rarely quantified in the data sources, broad categories describing the threat to the

127 population were recorded.

\section{Body mass data}

129 Body mass data were collated from a number of pre-existing databases and the

130 scientific literature (see Table S1 for a full list of sources utilised). When minimum

131 and maximum values where given, maximum was taken to ensure measures were

132 most likely those of mature individuals, and thus in line with commonly reported

133 measures from the other databases. Most data sources did not contain sex-specific

134 body mass measurements; however, where sex was indicated an average of the

135 male/female record was taken to account for dimorphism. Finally, where multiple

136 records of the same species were present between datasets, the mean was taken,

137 with all records then standardised to reflect a common unit (g, grams). 
138 For some taxa body mass data were unavailable, and so were estimated

139 using allometric regression equations using length measurements when possible

140 (Feldman et al., 2016; Stark et al., 2020). We used the general equation $W=a L^{b}$,

141 where $W=$ body mass, $L=$ length, and $a$ and $b$ are the intercept and slope of a

142 regression line over log $\square$ transformed weight $\square$ at $\square$ length data, respectively (Froese,

143 2009; Ripple et al., 2017). This method was applied to 47 amphibian species using

144 snout to vent length (SVL) records and clade-specific regression coefficients in

145 FishBase (Froese, 2009; Santini et al., 2018; Stark et al., 2020). A further 320 fish

146 species' mass were estimated, based on maximum total length ( $T L$ ) and regression

147 coefficients in FishBase (Froese, 2009). Where a measure other than TL was listed

148 (e.g., standard length (SL), fork length $(F L)$ ), regression coefficients were used to

149 convert these to total length before estimating body mass.

150 Trophic level data

151 We broadly classified species according to their diet in three main categories:

152 omnivores, carnivores, or herbivores. For amphibians, birds, mammals and reptiles,

153 we used the data from Etard et al. (2020). For bony and cartilaginous fishes we

154 inferred trophic levels from dietary information obtained from the parameter Feeding

155 Type contained in FishBase (Froese, 2009). Following the description in Froese

156 (2009) we considered: that herbivores were those species with between 2.0 and

157 2.19; carnivores had trophic levels equal to or greater than 2.8; and omnivores had

158 trophic levels between 2.2 and 2.79 .

Habitat breadth data

160 We estimated the habitat breath as the number of distinct habitats a species utilises

161 according to the IUCN habitat classification scheme (Daskalova et al., 2020; Etard et 
162 al., 2020). For amphibians, birds, mammals and reptiles, we used the data available

163 in Etard et al. (2020). For bony and cartilaginous fishes the number of habitats was

164 estimated using the rredlist package (Chamberlain, 2017).

165 Human population density data

166 To estimate the human influence across different latitudes, we obtained human

167 population density (inhabitants $/ \mathrm{km}^{2}$ ) information from HYDE3.2.001 (Hurtt et al.,

168 2011). The human population density represents the number of human habitants per

$169 \mathrm{~km}^{2}$ per grid cells of $5^{\prime}$ resolution. We used the country where the vertebrate

170 populations were studied to obtain the human population density data of each time 171 series.

172 Final dataset

173 When merging the above datasets with the data from the LPD, not all the species 174 had the same information available. The variables that were accessible for most of 175 the species was latitude (7826 time-series) and body mass (7492), followed by 176 human population density (7361), habitat breadth (6330) and trophic level (4833;

177 Figure 2a). When accounting for the combined availability of the variables, trophic 178 level was the variable with the less availability (Figure 2b). 1087 populations were 179 missing for the combined factors of trophic level and habitat breadth, 112 for trophic 180 level and body mass, 97 trophic level, body mass and habitat breath, 67 trophic level 181 and human population density, 48 trophic level, human population density and 182 habitat breadth and only 1 for trophic level, human population density and body 183 mass (Figure $2 \mathbf{b}$ ). Because of the low numbers of shared data between some of the 184 factors, we fitted each model (see Statistical Analysis) using the dataset with the 185 maximum number of data for each factor. That is, the size of the data set used for 
186 each of the models was different depending on the data availability for each of the

187 factors tested.

Statistical Analysis

189 To quantify the effects of latitude, body mass, habitat breath, human population

190 density, system, taxon, and trophic level we developed a set of multilevel Bayesian

191 models, using number of threats as a response variable. Body mass was log-

192 transformed and we used the absolute value of latitude. Body mass, latitude, habitat

193 breath, and human population density were added as numeric fixed effects and were

194 all standardised by subtracting the mean from each value and dividing by its

195 standard deviation. System, taxonomic class, and trophic level were considered as

196 categorical variables: the first having three levels, marine, terrestrial, and freshwater;

197 the second having five, amphibians, birds, bony fishes, cartilaginous fishes,

198 mammals and reptiles; and the third having three levels, omnivores, carnivorous and 199 herbivorous.

First, to test the effects of each of the aforementioned factors on the number

201 of threats at which vertebrate populations were exposed we fitted individual models

202 for each of the factors. Then, because we found that the system and taxonomic 203 group had an influence on the number of threats at which populations were exposed 204 (see Results), we fitted individual models for each combination of taxonomic group 205 and system. To account for the non-independence of repeated measurements for 206 each species we included a random intercept for each species. Given the lack of 207 phylogenetic signal in the number of threats at which the populations were exposed 208 (Figure S1) we did not include a phylogeny in these models. Each model with 209 categorical factors (e.g. system, taxon and trophic level) was fitted with a zero 
210 intercept to allow us to determine absolute effect of each category of the factors. The

211 general structure of the models was:

212

213

214

215

216

217

218

219

220

221

2221000 iterations. Convergence was assessed visually by examining trace plots and

223 using Rhat values (the ratio of the effective sample size to the overall number of

224 iterations, with values close to one indicating convergence).

\section{Results}

226 General models

227 The number of threats which populations are exposed to is affected by a number of

228 factors (Figure 3). Among all the systems, freshwater and terrestrial species are 
229 exposed to a higher number of threats (Figure 3a; Table S3). Reptiles are the

230 taxonomic class exposed to the highest number of threats, followed by amphibians,

231 birds, mammals, cartilaginous fishes, and then bony fishes respectively (Figure $3 \mathbf{b}$;

232 Table S3). All trophic levels show similar degree of exposition to multiple threats, 233 with omnivores slightly less at risk than carnivores or herbivores (Figure 3c; Table 234 S3). Across all taxa and systems there is low evidence for the influence of body 235 mass on the number of threats (Figure 3d; Table S3). On the contrary, latitude has a 236 clear effect on the number of threats, with populations at higher latitudes being 237 exposed to a lower number of threats (Figure 3e; Table S3). However, human 238 population densities have a less clear effect, with a low certainty that the effect size 239 is different to zero (Figure $3 \mathbf{f}$; Table S3). Finally, there is moderate evidence that 240 species with larger habitat breadth are exposed to a lower number of threats (Figure $2413 \mathbf{g}$; Table S3).

\section{System and taxa models}

243 The influence of body mass on the number of threats to which populations are 244 exposed varies across different systems and taxa (Figure 4). The number of threats 245 decreases with body mass in amphibians and reptiles independently of the system 246 they inhabit (Figure 4; Table S4). However, these estimates are highly uncertain for 247 freshwater amphibians and reptiles, and marine reptiles (Table S4). For all the other 248 taxonomic groups and systems, the number of threats increases with body mass 249 (Figure 4; Table S4), with high uncertainty in freshwater birds, freshwater and marine 250 bony fishes, and marine mammals (Table S4).

In line with the results of the general models, for most systems and taxa the 252 number of threats decreases at higher latitudes (Figure 5). However, for some 
253 system and taxa combinations (notably terrestrial amphibians, birds, marine bony 254 fishes, marine cartilaginous fishes, and marine reptiles) the slope estimates are 255 again uncertain (Table S5). Our results also suggest that the number of threats could 256 increase with latitude in freshwater amphibians, freshwater mammals, and terrestrial 257 reptiles, although again these estimates were highly uncertain (Table S5).

\section{Discussion}

259 Identifying the factors determining the predisposition of species to be exposed to 260 multiple threats is crucial to maintain biodiversity (Gunderson et al., 2016; Maxwell et 261 al., 2016). To date, most studies have focused on identifying the factors that make 262 species more prone to extinction, rather than to multiple threats (Purvis et al., 2000; 263 Cardillo et al., 2005; Atwood et al., 2020). Consequently, we currently lack 264 understanding of the (a)biotic factors which predispose species to multiple threats, 265 what could help pre-emptively design conservation actions. Here, using a global 266 collation of threat, trait, and geographic data from vertebrate populations, we show 267 that a suite of factors can be used to anticipate the number of threats which 268 vertebrate populations are exposed to. Among these, latitude and body mass are the 269 most readily available and with a strong predictive power. These results are the first 270 necessary step to develop predictive approaches to anticipate the number of threats 271 impacting wildlife populations using minimal data.

273 are exposed to. Although we hypothesised that the potential reason for this pattern 274 could be that the largest number of people live in lower latitudes (Kummu \& Varis, 275 2011; Figure S4), human population density was a weak driver of threat number. 276 Human population density has long been considered a proxy for anthropogenic 
277 disturbance factors (Santini et al., 2017), and arguably the main cause for the 278 ongoing sixth mass extinction event (Ceballos et al., 2020). This premise is based on 279 the assumption that areas with high human density increase the numbers of threats 280 to populations, driving populations beyond the point of recovery (Symes et al., 2018). 281 However, our results suggest that human population density fails to capture the 282 patterns of threats distribution in our global data, and that latitude encapsulates 283 additional latent predictors which predispose populations to be impacted by multiple 284 threats.

Global and local threats are distributed unevenly across the planet (Bowler et 286 al., 2020). For instance, our results suggest that terrestrial and freshwater species 287 are exposed to a higher number of threats compared to marine ones. These findings 288 are in line with the millennia-long human impacts of terrestrial and freshwater 289 systems (McCauley et al., 2015; Van Der Kaars et al., 2017), but may also reflect the 290 difficulty of monitoring species in marine environments. In addition, the presence of 291 threats affecting species can vary within and across countries (Harfoot et al., 2021), 292 often in relation to local governmental conservation policies (Barnes et al., 2016; 293 Amano et al., 2018). Climate change also shows complex spatial patterns, with some 294 mid-latitude regions projected to experience the highest increase in the temperature 295 of the hottest days, while the Arctic is expected to suffer the highest increase in the 296 temperature of the coldest days (IPCC, 2021). In these areas, where the impacts of 297 climate change are likely to become more intense, the interaction with other threats 298 is likely to increase in the coming decades (Bennett et al., 2015). Given the 299 complexity of accounting for such multiple spatial drivers, latitude can provide a 300 simple proxy for multiple threats exposition. 
We also show that in most vertebrate groups larger species are exposed to a

302 greater number of threats. The greater vulnerability of larger species is often

303 attributed to different intrinsic and extrinsic factors (Fisher \& Owens, 2004; Cardillo et

304 al., 2005). For instance, larger species are disproportionally targeted for exploitation

305 and more affected by invasive species (Bennett \& Owens, 1997; Duncan et al.,

306 2002). Also, species with larger body size often occupy higher trophic levels, which

307 are also associated with higher extinction risk (Böhm et al., 2016; Collen et al.,

308 2011). However, our results support recent research (Atwood et al., 2020) showing

309 that species with higher trophic levels are not necessarily exposed to a larger

310 number of threats. Because body size was the most readily available trait, and its

311 tight link with the life history of species (Gaillard et al., 1989), conservation status

312 (Ripple et al., 2017) and ecological processes (White et al., 2007), our findings

313 validate its use as a proxy for multiple threats exposition.

314 Amphibians and reptiles were the exception to the abovementioned pattern,

315 with body size being inversely related with number of threats. These pattern may be

316 driven by the nature of the threats affecting them. Both groups are mostly affected by

317 habitat loss, while mammals, birds and fishes are mostly impacted by exploitation

318 (Díaz et al., 2019; Harfoot et al., 2021). While larger individuals are often the target

319 of exploitation (Pauly et al., 1998; Duncan et al., 2002), the lower dispersal ability

320 and more constrained range sizes of small organisms could make them more

321 vulnerable to habitat loss (Cardillo et al., 2008; González-Suárez et al., 2013; Pacifici

322 et al., 2017). Moreover, our results suggest amphibians and reptiles are facing the

323 largest number of threats, mirroring recent reports suggesting that these are the

324 vertebrate groups experiencing the most dramatic decline (Daskalova et al., 2020).

325 Despite these findings, amphibians and reptiles are the most understudied 
326 vertebrate groups in global conservation assessments (Alroy, 2015). For instance,

327 about $25 \%$ of known reptiles and amphibian species are classified as data deficient

328 by the IUCN Red List (IUCN, 2021). Hence, our results adds evidence for the need

329 of global efforts to study these groups, to better understand the causes of their

330 decline and develop effective conservation policies (Gibbons et al., 2000). Our

331 findings also highlight the importance of understanding the mechanisms that

332 predispose reptiles and amphibians to multiple threats as a key area for future 333 research.

Although our research uses the largest compilation of population-level threat

335 data, there are still gaps in our understanding of the drivers of multiple threats. While

336 the LPD draws from published literature, this also means its data inherits any biases

337 derived from its sources. This has resulted in the over-representation of well-studied

338 regions and taxa, with research also inclined towards populations within protected

339 areas and terrestrial ecosystems (Loh et al., 2005; McRae et al., 2017). In addition,

340 while here we only focused on the number of threats, their type (e.g. exploitation,

341 habitat loss), intensity and/or frequency also has a major influence on the population

342 trends and this information was not readily available. For instance, different threats,

343 or the same threat with different intensity and/or frequency, might interact in different

344 ways, causing different impacts on the populations (Darling \& Côté, 2008; Côté et

345 al., 2016; Orr et al., 2020). Not only that, but the timing (when threats impacted the

346 population over the time series) and the synchrony (the overlap on time between

347 multiple threats) of the threats might have a strong influence on populations

348 (Johnstone et al., 2016; Jackson et al., 2021). The limited data available on

349 disturbances nature and timing at the population-level hampered including such

350 information in our analyses. To this end, we advocate explicit reference to threats 
351 within ecological research to enable the expansion of current databases and to keep

352 multiple threats processes at the forefront of developing research.
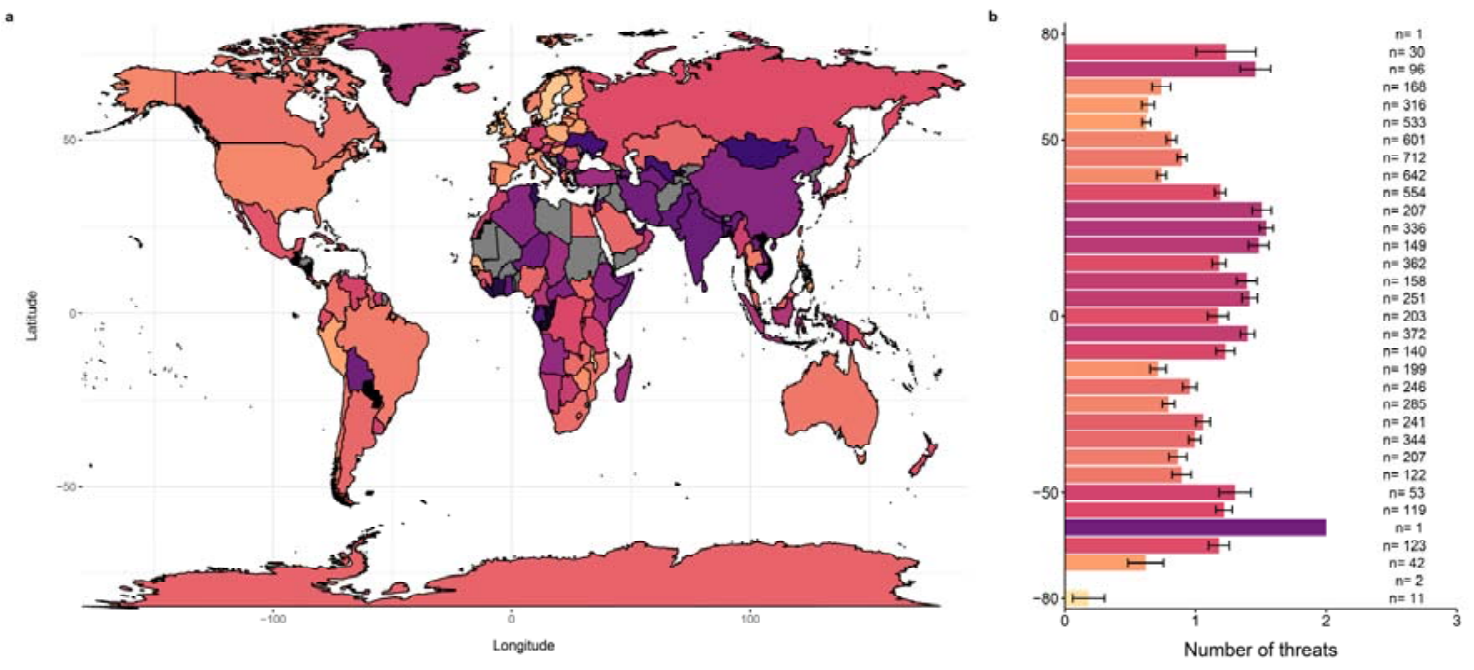

Figure 1. Global distribution of the mean number of threats by country and

355 latitude. Global overview of the mean number of threats, (a) within each country and

356 (b) by latitude with numbers alongside bars representing sample sizes for each $5^{\circ}$ 357 latitude bin. 
a

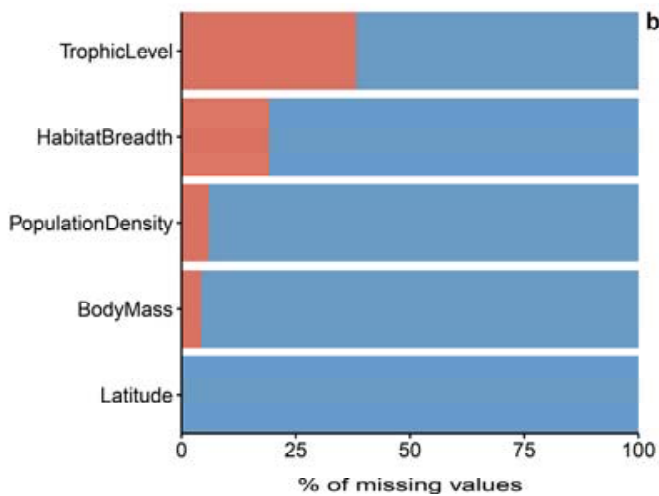

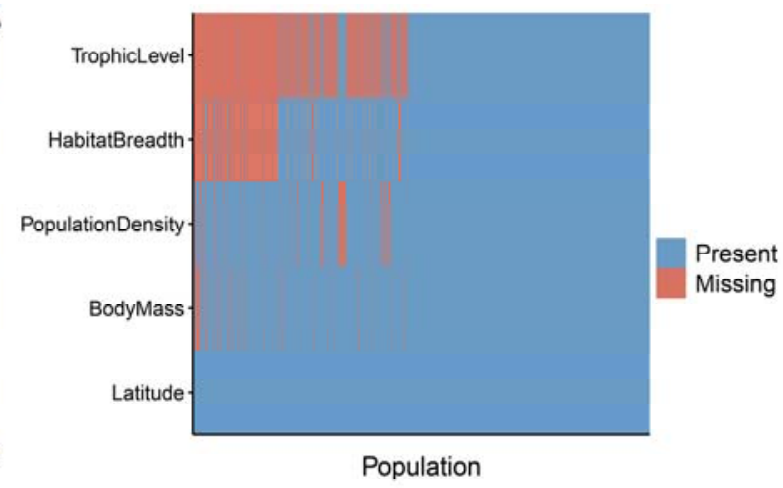

363 Figure 2. Patterns of missingness in the data. The variable the most available for 364 the species in the subset of data from the Living Planet Database containing threat 365 information was body mass. (a) Proportion of missing and present values of the 366 different variables. (b) Total presence and absence of the different variables across 367 the dataset. 

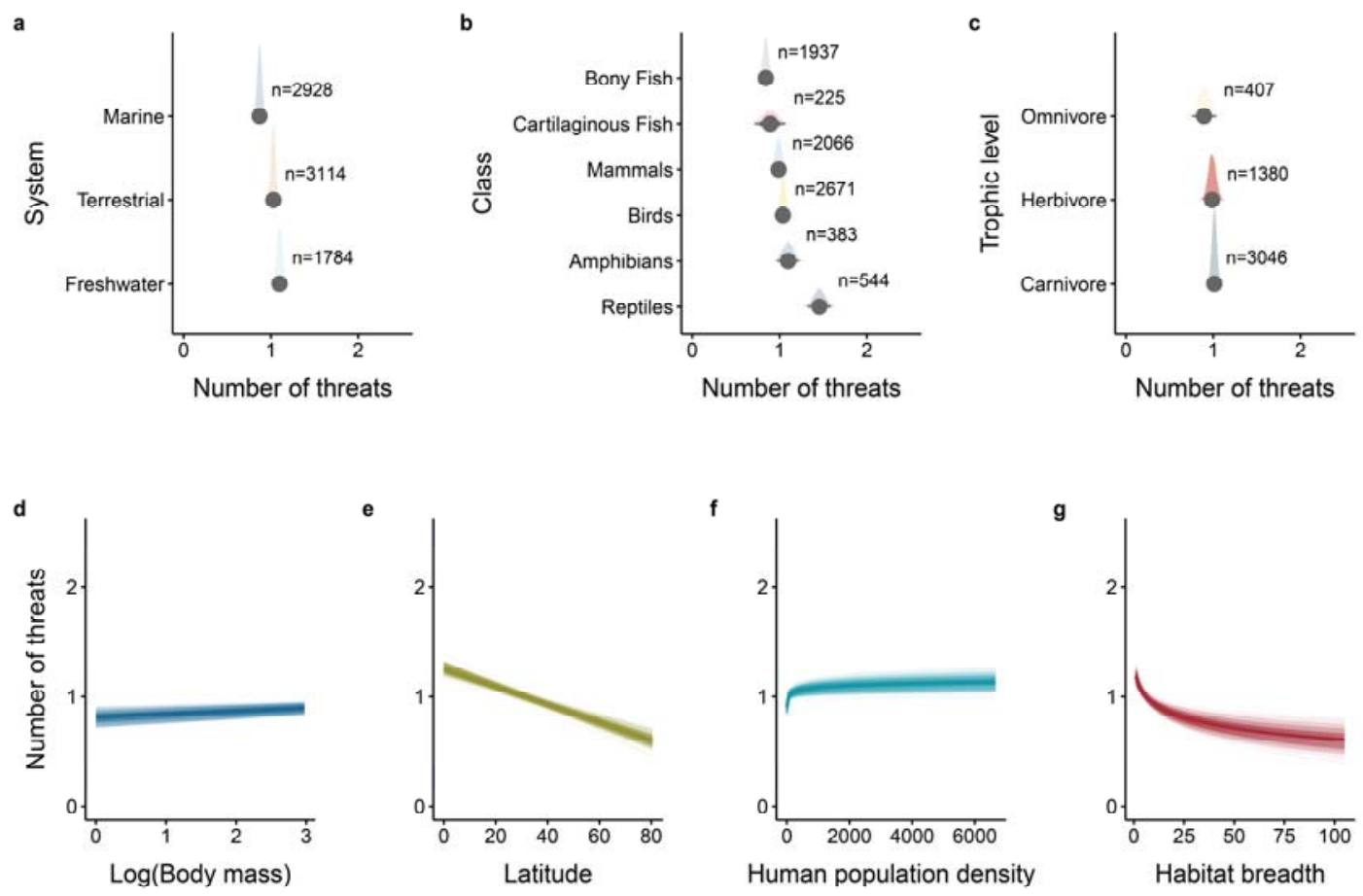

371 Figure 3. Factors influencing the number of threats at which vertebrate

372 populations are exposed. (a-c) density plots of posterior distributions for the

373 effects of (a) system, (b) taxonomic class, and (c) trophic level, on the number of

374 threats. Each density plot is based on 1,000 samples from the posterior distribution

375 of the slope estimates (Table S2). The reported values are the highest posterior

376 density median values (circles), with 80\% (thickest bars), 90\%, and 95\% (thinnest

377 bars) uncertainty intervals. $\mathbf{n}$ represents the sample size for that given threat in the 378 original dataset. ( $\mathbf{d}-\mathbf{g})$ predictions of the number of threats as a function of the (d) 379 body mass (g), (e) latitude (absolute value), (f) human population density and (g) 380 habitat breadth. Lines represent the predictions from the multilevel Bayesian models 381 (Table S2), where thin lines correspond to the predictions drawn from each of the 382250 posterior samples of the model, and the thick line represents the mean outcome 383 of the model. 


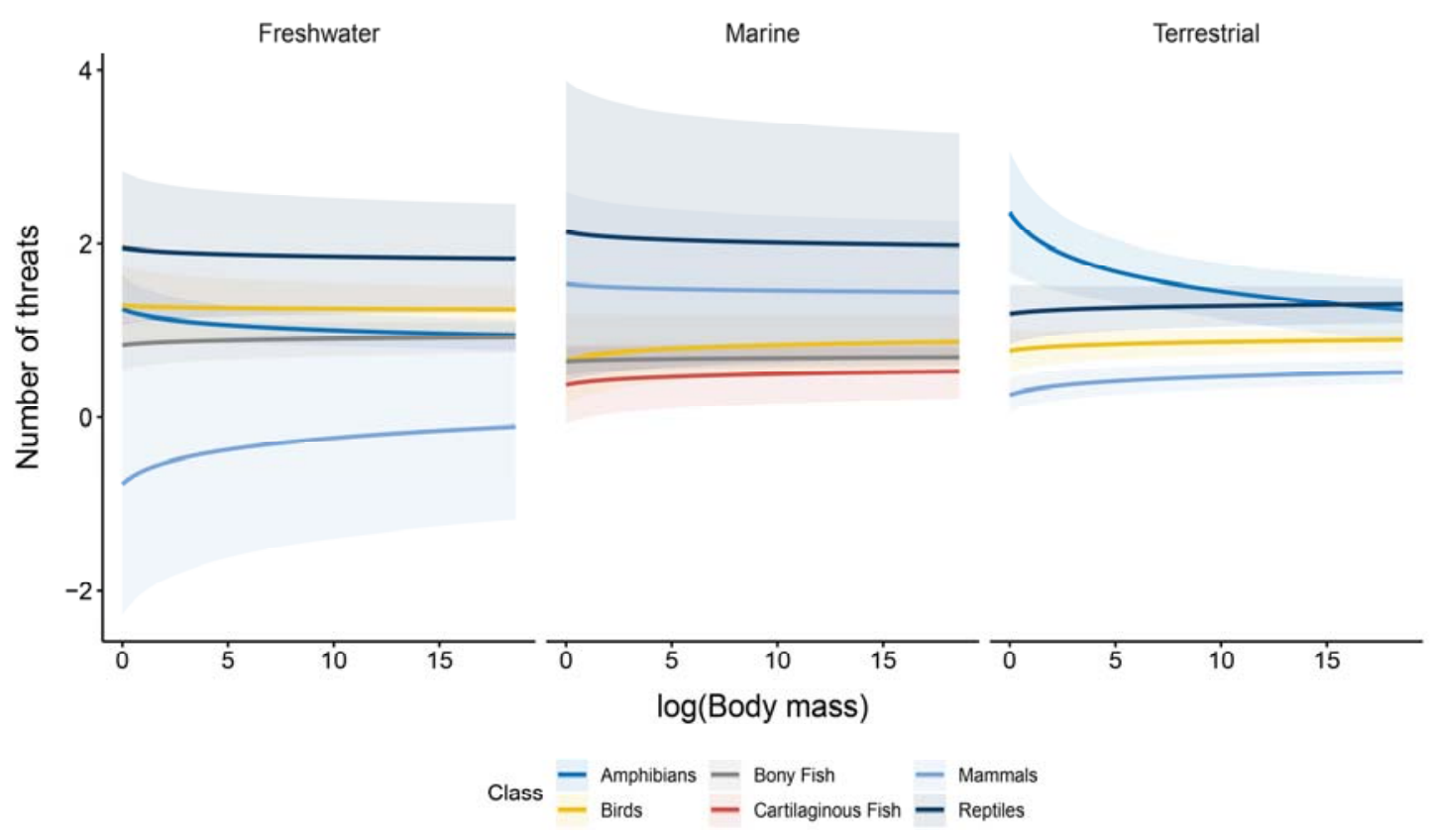

388 Figure 4. Model predictions of threat number as a function of body mass.

389 Multilevel Bayesian model predictions of the number of threats as a function of body

390 mass (in grams). Ribbons display 95\% confidence intervals.

391

392 


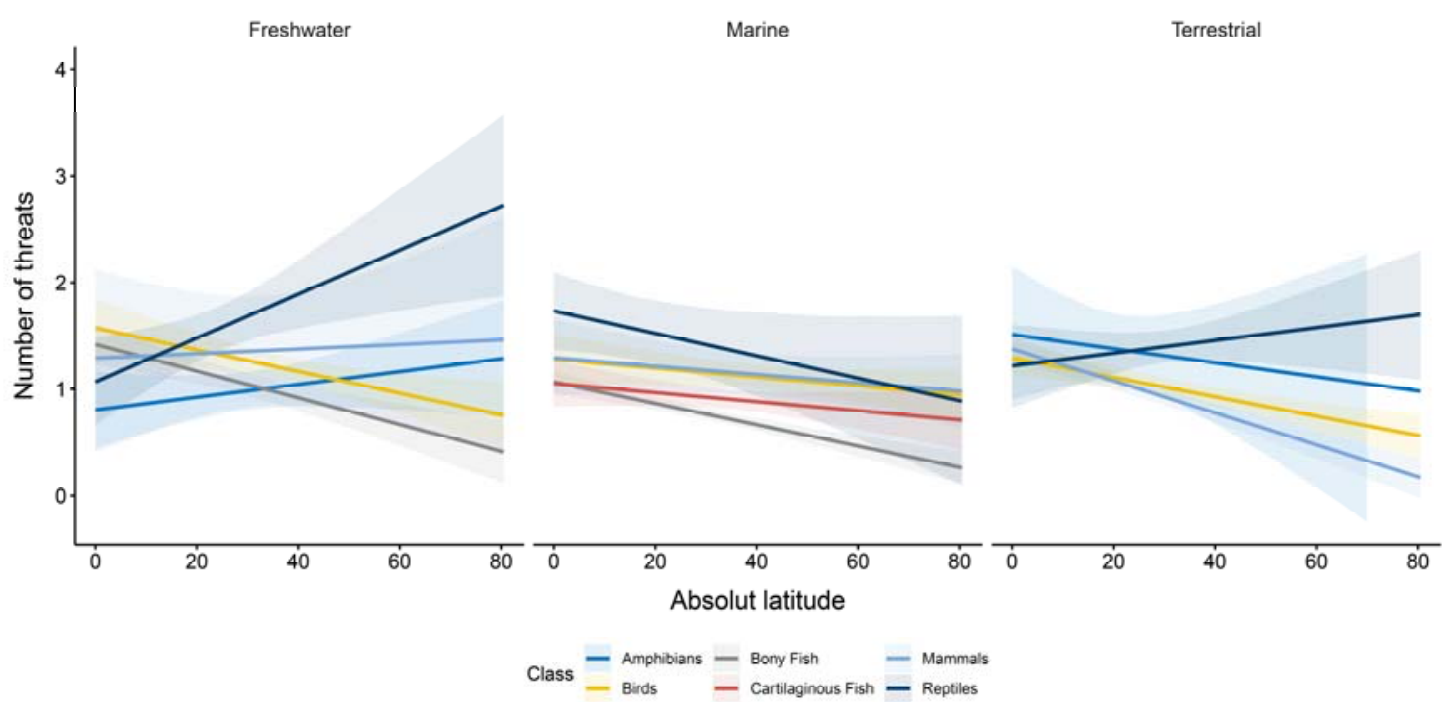

396 Figure 5. Latitudinal trends of the number of threats. Multilevel Bayesian model

397 predictions of the number of threats as a function of the absolute value of latitude.

398 Ribbons display $95 \%$ confidence intervals. 


\section{References}

402

403

404

405

406

407

408

409

410

411

412

413

414

415

416

417

418

419

420

421

422

423

424

425

426

427

428

429

430

431

432

433

434

435

436

437

438

439

440

441

442

443

444

445

446

447

448
Alroy, J. (2015) Current extinction rates of reptiles and amphibians. Proceedings of the National Academy of Sciences, 112, 13003-13008.

Amano, T., Székely, T., Sandel, B., Nagy, S., Mundkur, T., Langendoen, T., Blanco, D., Soykan, C.U. \& Sutherland, W.J. (2018) Successful conservation of global waterbird populations depends on effective governance. Nature, 553, 199202.

Atwood, T.B., Valentine, S.A., Hammill, E., McCauley, D.J., Madin, E.M., Beard, K.H. \& Pearse, W.D. (2020) Herbivores at the highest risk of extinction among mammals, birds, and reptiles. Science advances, 6, eabb8458.

Barnes, M.D., Craigie, I.D., Harrison, L.B., Geldmann, J., Collen, B., Whitmee, S., Balmford, A., Burgess, N.D., Brooks, T. \& Hockings, M. (2016) Wildlife population trends in protected areas predicted by national socio-economic metrics and body size. Nature Communications, 7, 1-9.

Batt, R.D., Morley, J.W., Selden, R.L., Tingley, M.W. \& Pinsky, M.L. (2017) Gradual changes in range size accompany long-term trends in species richness. Ecology Letters, 20, 1148-1157.

Bennett, J.R., Shaw, J.D., Terauds, A., Smol, J.P., Aerts, R., Bergstrom, D.M., Blais, J.M., Cheung, W.W., Chown, S.L. \& Lea, M.-A. (2015) Polar lessons learned: long-term management based on shared threats in Arctic and Antarctic environments. Frontiers in Ecology and the Environment, 13, 316-324.

Bennett, P.M. \& Owens, I.P. (1997) Variation in extinction risk among birds: chance or evolutionary predisposition? Proceedings of the Royal Society of London. Series B: Biological Sciences, 264, 401-408.

Birk, S., Chapman, D., Carvalho, L., Spears, B.M., Andersen, H.E., Argillier, C., Auer, S., Baattrup-Pedersen, A., Banin, L. \& Beklioğlu, M. (2020) Impacts of multiple stressors on freshwater biota across spatial scales and ecosystems. Nature Ecology \& Evolution, 4, 1060-1068.

Böhm, M., Williams, R., Bramhall, H.R., McMillan, K.M., Davidson, A.D., Garcia, A., Bland, L.M., Bielby, J. \& Collen, B. (2016) Correlates of extinction risk in squamate reptiles: the relative importance of biology, geography, threat and range size. Global Ecology and Biogeography, 25, 391-405.

Bowler, D.E., Bjorkman, A.D., Dornelas, M., Myers-Smith, I.H., Navarro, L.M., Niamir, A., Supp, S.R., Waldock, C., Winter, M. \& Vellend, M. (2020) Mapping human pressures on biodiversity across the planet uncovers anthropogenic threat complexes. People and Nature, 2, 380-394.

Bürkner, P.-C. (2017) Advanced Bayesian multilevel modeling with the R package brms. arXiv preprint arXiv:1705.11123.

Cardillo, M., Mace, G.M., Gittleman, J.L., Jones, K.E., Bielby, J. \& Purvis, A. (2008) The predictability of extinction: biological and external correlates of decline in mammals. Proceedings of the Royal Society B: Biological Sciences, 275, 1441-1448.

Cardillo, M., Mace, G.M., Jones, K.E., Bielby, J., Bininda-Emonds, O.R.P., Sechrest, W., Orme, C.D.L. \& Purvis, A. (2005) Multiple causes of high extinction risk in large mammal species. Science, 309, 1239-1241.

Ceballos, G., Ehrlich, P.R. \& Raven, P.H. (2020) Vertebrates on the brink as indicators of biological annihilation and the sixth mass extinction. Proceedings of the National Academy of Sciences, 117, 13596-13602. 
449 Chamberlain, S. (2017) rredlist: 'IUCN' Red List Client. $R$ package version 0.4.0. https://CRAN.R-project.org/package=rredlist.

Collen, B., McRae, L., Deinet, S., De Palma, A., Carranza, T., Cooper, N., Loh, J. \& Baillie, J.E. (2011) Predicting how populations decline to extinction. Philosophical Transactions of the Royal Society B: Biological Sciences, 366, 2577-2586.

Collen, B.E.N., Loh, J., Whitmee, S., McRAE, L., Amin, R. \& Baillie, J.E. (2009) Monitoring change in vertebrate abundance: the Living Planet Index. Conservation Biology, 23, 317-327.

Côté, I.M., Darling, E.S. \& Brown, C.J. (2016) Interactions among ecosystem stressors and their importance in conservation. Proceedings of the Royal Society B: Biological Sciences, 283, 20152592-20152592.

Darling, E.S. \& Côté, I.M. (2008) Quantifying the evidence for ecological synergies. Ecology letters, 11, 1278-1286.

Daskalova, G.N., Myers-Smith, I.H. \& Godlee, J.L. (2020) Rare and common vertebrates span a wide spectrum of population trends. Nature Communications, 11, 4394.

Di Marco, M., Collen, B., Rondinini, C. \& Mace, G.M. (2015) Historical drivers of extinction risk: using past evidence to direct future monitoring. Proceedings of the Royal Society B: Biological Sciences, 282, 20150928.

Díaz, S., Settele, J., Brondízio, E.S., Ngo, H.T., Agard, J., Arneth, A., Balvanera, P., Brauman, K.A., Butchart, S.H. \& Chan, K.M. (2019) Pervasive human-driven decline of life on Earth points to the need for transformative change. Science, 366.

Dirzo, R., Young, H.S., Galetti, M., Ceballos, G., Isaac, N.J. \& Collen, B. (2014) Defaunation in the Anthropocene. Science, 345, 401-406.

Duncan, R.P., Blackburn, T.M. \& Worthy, T.H. (2002) Prehistoric bird extinctions and human hunting. Proceedings of the Royal Society of London. Series B: Biological Sciences, 269, 517-521.

Ehrlén, J. \& Morris, W.F. (2015) Predicting changes in the distribution and abundance of species under environmental change. Ecology letters, 18, 303314.

Etard, A., Morrill, S. \& Newbold, T. (2020) Global gaps in trait data for terrestrial vertebrates. Global Ecology and Biogeography, 29, 2143-2158.

Feldman, A., Sabath, N., Pyron, R.A., Mayrose, I. \& Meiri, S. (2016) Body sizes and diversification rates of lizards, snakes, amphisbaenians and the tuatara. Global Ecology and Biogeography, 25, 187-197.

Fisher, D.O. \& Owens, I.P. (2004) The comparative method in conservation biology. Trends in Ecology and Evolution, 19, 391-398.

Froese, R. (2009) FishBase. world wide web electronic publication. http://www. fishbase. org.

Gaillard, J.-M., Pontier, D., Allainé, D., Lebreton, J.D., Trouvilliez, J. \& Clobert, J. (1989) An analysis of demographic tactics in birds and mammals. Oikos, 56, 59-76.

Gibbons, J.W., Scott, D.E., Ryan, T.J., Buhlmann, K.A., Tuberville, T.D., Metts, B.S., Greene, J.L., Mills, T., Leiden, Y. \& Poppy, S. (2000) The Global Decline of Reptiles, Déjà Vu Amphibians: Reptile species are declining on a global scale. Six significant threats to reptile populations are habitat loss and degradation, introduced invasive species, environmental pollution, disease, unsustainable use, and global climate change. BioScience, 50, 653-666. 
499

500

501

502

503

504

505

506

507

508

509

510

511

512

513

514

515

516

517

518

519

520

521

522

523

524

525

526

527

528

529

530

531

532

533

534

535

536

537

538

539

540

541

542

543

544

545

546

547

González-Suárez, M., Gómez, A. \& Revilla, E. (2013) Which intrinsic traits predict vulnerability to extinction depends on the actual threatening processes. Ecosphere, 4, 1-16.

Gunderson, A.R., Armstrong, E.J. \& Stillman, J.H. (2016) Multiple stressors in a changing world: the need for an improved perspective on physiological responses to the dynamic marine environment. Annual review of marine science, 8, 357-378.

Halpern, B.S., Frazier, M., Potapenko, J., Casey, K.S., Koenig, K., Longo, C., Lowndes, J.S., Rockwood, R.C., Selig, E.R. \& Selkoe, K.A. (2015) Spatial and temporal changes in cumulative human impacts on the world's ocean. Nature communications, 6, 1-7.

Harfoot, M.B., Johnston, A., Balmford, A., Burgess, N.D., Butchart, S.H., Dias, M.P., Hazin, C., Hilton-Taylor, C., Hoffmann, M. \& Isaac, N.J. (2021) Using the IUCN Red List to map threats to terrestrial vertebrates at global scale. Nature Ecology \& Evolution, 1-10.

Hodgson, E.E., Essington, T.E. \& Halpern, B.S. (2017) Density dependence governs when population responses to multiple stressors are magnified or mitigated. Ecology, 98, 2673-2683.

Hughes, T.P., Kerry, J.T., Álvarez-Noriega, M., Álvarez-Romero, J.G., Anderson, K.D., Baird, A.H., Babcock, R.C., Beger, M., Bellwood, D.R. \& Berkelmans, R. (2017) Global warming and recurrent mass bleaching of corals. Nature, 543, 373.

Hurtt, G.C., Chini, L.P., Frolking, S., Betts, R.A., Feddema, J., Fischer, G., Fisk, J.P., Hibbard, K., Houghton, R.A. \& Janetos, A. (2011) Harmonization of land-use scenarios for the period 1500-2100: 600 years of global gridded annual landuse transitions, wood harvest, and resulting secondary lands. Climatic change, 109, 117-161.

IPCC (2021) Climate Change 2021: The Physical Science Basis. Contribution of Working Group I to the Sixth Assessment Report of the Intergovernmental Panel on Climate Change [Masson-Delmotte, V., P. Zhai, A. Pirani, S. L. Connors, C. Péan, S. Berger, N. Caud, Y. Chen, L. Goldfarb, M. I. Gomis, M. Huang, K. Leitzell, E. Lonnoy, J. B. R. Matthews, T. K. Maycock, T. Waterfield, O. Yelekçi, R. Yu and B. Zhou (eds.)]., Cambridge University Press.

IUCN 2021. The IUCN Red List of Threatened Species. Version 2021-1. IUCN Red List of Threatened Species.

Jackson, M.C., Pawar, S. \& Woodward, G. (2021) The temporal dynamics of multiple stressor effects: From individuals to ecosystems. Trends in Ecology and Evolution, 36, 402-410.

Johnstone, J.F., Allen, C.D., Franklin, J.F., Frelich, L.E., Harvey, B.J., Higuera, P.E., Mack, M.C., Meentemeyer, R.K., Metz, M.R., Perry, G.L., Schoennagel, T. \& Turner, M.G. (2016) Changing disturbance regimes, ecological memory, and forest resilience. Frontiers in Ecology and the Environment, 14, 369-378.

Kroeker, K.J., Kordas, R.L., Crim, R.N. \& Singh, G.G. (2010) Meta-analysis reveals negative yet variable effects of ocean acidification on marine organisms. Ecology Letters, 13, 1419-1434.

Kummu, M. \& Varis, O. (2011) The world by latitudes: A global analysis of human population, development level and environment across the north-south axis over the past half century. Applied geography, 31, 495-507. 
548

549

550

551

552

553

554

555

556

557

558

559

560

561

562

563

564

565

566

567

568

569

570

571

572

573

574

575

576

577

578

579

580

581

582

583

584

585

586

587

588

589

590

591

592

593

594

595

596

597

Loh, J., Green, R.E., Ricketts, T., Lamoreux, J., Jenkins, M., Kapos, V. \& Randers, J. (2005) The Living Planet Index: using species population time series to track trends in biodiversity. Philosophical Transactions of the Royal Society B: Biological Sciences, 360, 289-295.

Malcolm, J.R., Liu, C., Neilson, R.P., Hansen, L. \& Hannah, L.E.E. (2006) Global warming and extinctions of endemic species from biodiversity hotspots. Conservation biology, 20, 538-548.

Maxwell, S.L., Fuller, R.A., Brooks, T.M. \& Watson, J.E. (2016) Biodiversity: The ravages of guns, nets and bulldozers. Nature News, 536, 143.

McCauley, D.J., Pinsky, M.L., Palumbi, S.R., Estes, J. a., Joyce, F.H. \& Warner, R.R. (2015) Marine defaunation: Animal loss in the global ocean. Science, 347, 247-254.

McRae, L., Deinet, S. \& Freeman, R. (2017) The diversity-weighted Living Planet Index: controlling for taxonomic bias in a global biodiversity indicator. PloS one, 12, e0169156.

Newbold, T., Hudson, L.N., Hill, S.L., Contu, S., Lysenko, I., Senior, R.A., Börger, L., Bennett, D.J., Choimes, A. \& Collen, B. (2015) Global effects of land use on local terrestrial biodiversity. Nature, 520, 45-50.

Orr, J.A., Vinebrooke, R.D., Jackson, M.C., Kroeker, K.J., Kordas, R.L., MantykaPringle, C., Van den Brink, P.J., De Laender, F., Stoks, R. \& Holmstrup, M. (2020) Towards a unified study of multiple stressors: divisions and common goals across research disciplines. Proceedings of the Royal Society B: Biological Sciences, 287, 20200421.

Pacifici, M., Visconti, P., Butchart, S.H.M., Watson, J.E.M., Cassola, F.M. \& Rondinini, C. (2017) Species' traits influenced their response to recent climate change. Nature Climate Change, 7, 205-208.

Pauly, D., Christensen, V., Dalsgaard, J., Froese, R. \& Torres, F. (1998) Fishing down marine food webs. Science, 279, 860-863.

Purvis, A., Gittleman, J.L., Cowlishaw, G. \& Mace, G.M. (2000) Predicting extinction risk in declining species. Proceedings of the royal society of London. Series $B$ : Biological Sciences, 267, 1947-1952.

R Core Team (2020) R: A language and environment for statistical computing. $R$ Foundation for Statistical Computing, Vienna, Austria. URL,.

Ripple, W.J., Wolf, C., Newsome, T.M., Hoffmann, M., Wirsing, A.J. \& McCauley, D.J. (2017) Extinction risk is most acute for the world's largest and smallest vertebrates. Proceedings of the National Academy of Sciences, 114, 1067810683.

Santini, L., BENÍTEZ-LÓPEZ, A., Ficetola, G.F. \& Huijbregts, M.A. (2018) Lengthmass allometries in amphibians. Integrative zoology, 13, 36-45.

Santini, L., González-Suárez, M., Rondinini, C. \& Di Marco, M. (2017) Shifting baseline in macroecology? Unravelling the influence of human impact on mammalian body mass. Diversity and Distributions, 23, 640-649.

Scholes, R.J., Montanarella, L., Brainich, E., Barger, N., ten Brink, B., Cantele, M., Erasmus, B., Fisher, J., Gardner, T. \& Holland, T.G. (2018) IPBES (2018): Summary for policymakers of the assessment report on land degradation and restoration of the Intergovernmental Science-Policy Platform on Biodiversity and Ecosystem Services.

Stark, G., Pincheira-Donoso, D. \& Meiri, S. (2020) No evidence for the 'rate-of-living'theory across the tetrapod tree of life. Global Ecology and Biogeography, 29, 857-884. 
598 Steffen, W., Grinevald, J., Crutzen, P. \& McNeill, J. (2011) The Anthropocene: 599 conceptual and historical perspectives. Philosophical transactions. Series A, $600 \quad$ Mathematical, physical, and engineering sciences, 369, 842-67.

601 Sunday, J.M., Bates, A.E. \& Dulvy, N.K. (2012) Thermal tolerance and the global 602 redistribution of animals. Nature Climate Change, 2, 686-690.

603 Symes, W.S., Edwards, D.P., Miettinen, J., Rheindt, F.E. \& Carrasco, L.R. (2018) $604 \quad$ Combined impacts of deforestation and wildlife trade on tropical biodiversity 605 are severely underestimated. Nature communications, 9, 1-9.

606 Van Der Kaars, S., Miller, G.H., Turney, C.S., Cook, E.J., Nürnberg, D., Schönfeld, 607 J., Kershaw, A.P. \& Lehman, S.J. (2017) Humans rather than climate the 608 primary cause of Pleistocene megafaunal extinction in Australia. Nature Communications, 8, 1-7.

613 Wolf, C. \& Ripple, W.J. (2016) Prey depletion as a threat to the world's large 614 carnivores. Royal Society Open Science, 3, 160252. 